\title{
Freie Vereinigung der Schweizer Pathologen
}

18. Jahresversammlung in Davos, 21. und 22. Juni 1952

Association libre des Pathologistes Suisses

18e Assemblée annuelle à Davos, ies 21 et 22 juin 1952

Jahrespräsident/Président annuel : H. U. Zollinger.

Verzeichnis der Vorlräge - Liste des Communications

Studer, A., und B. Fust, Protrahierte und therapeutische Wirkung von Rimifon bei

experimenteller Mäusetuber-

kulose 612

Diskussion: Berblinger, v. Albertini. Studer (Schlußwort).

Hedinger, Chr., Zur Histopathologie der sog. Katzenkrank-heit, einer benignen

Viruslymphadenitis (Maladie des griffes de chat, lymphoréticulose bénigne d'inoculation) 622

Diskussion: fiüttner.

Rüttner, J. R., Über Asbestose- und Pseudoasbestosekörper-

chen 628

Stünzí, H., Herzbasisgeschwülste beim Hund

Aufdermaur, M., Coronarthrombose bei Kranzarterienrissen durch physische und psychische Belastung (erschienen

in Schweiz. Med. Wschr. 1952, Nr. 42) 637

Rutíshauser, E., Knochen-Phlebographie 638

Rutishauser, E., und R. Feiiardent, Schnittrekonstruktion

glomusartiger Bildungen (Anastomositis) der Lunge . 641

Albertini, A. v., Elektronenmikroskopische Untersuchungen

am Methylcholanthrenkarzinom der Maushaut . . 645

Diskussion: Nicod, v. Albertini (Schlußwort).

Berblinger, W., Die feuchte Konservierung der Leiche durch

Gefäßinjektion651

Riniker, P., Zur Beziehung zwischen Silikose und Tuberku-

lose 657

Diskussion: Nicod, Rüttner.

Nicod, J. L., Les tumeurs mésodermiques à différenciation

épithéliale 661

Discussion: Werthemann, v. Albertini, Nicod (Conclusion).

Zollinger, H. U., Experimentelle Erzeugung maligner Nieren-

kapseltumoren bei der Ratte durch Druckreiz (Plastic-

Kapseln) $\quad 666$

Diskussion: u. Albertini, Berblinger. 